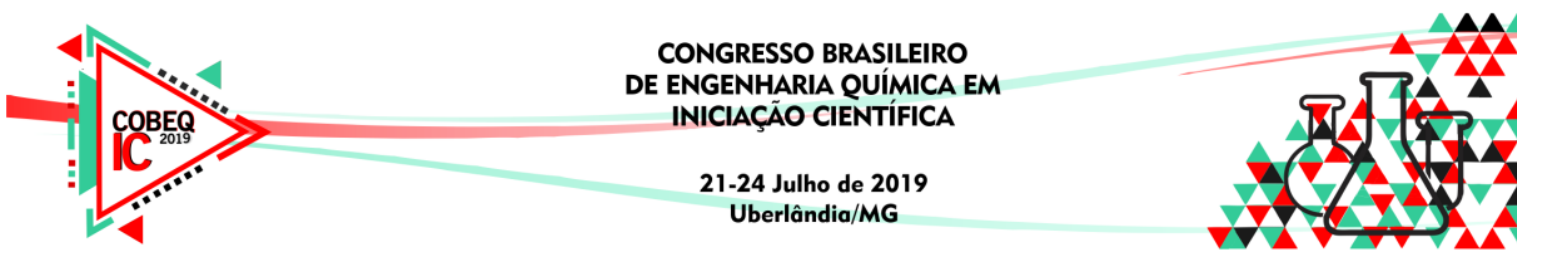

\title{
ESTUDO DA DETERMINAÇÃO DA UMIDADE DE SINTER FEED EM MEDIDOR DE INFRAVERMELHO, COMO TÉCNICA ALTERNATIVA À PROPOSTA NA NORMA NBR ISO 3087:2011
}

\author{
L. G. F. SANTOS ${ }^{1}$, V.A.F. AGUIAR ${ }^{1}$ e M. C. MANCINI ${ }^{1}$ \\ ${ }^{1}$ Universidade Federal Rural do Rio de Janeiro, Instituto de Tecnologia \\ Departamento de Engenharia Química \\ e-mail para contato: mancinimc@gmail.com e sfonsecaluan@gmail.com
}

\begin{abstract}
RESUMO - No presente trabalho foi realizado um estudo comparativo entre a metodologia de determinação de umidade de sinter feed em estufa convencional, conforme estabelecido na norma NBR ISO 3087:2011, e em um analisador de umidade por infravermelho da marca Gehaka, modelo IV 2000. Nos experimentos, realizados em quadruplicada, as amostras de sinter feed, fornecido pela Ferrous Resources do Brasil, foram submetidas à secagem na estufa convencional a $105^{\circ} \mathrm{C}$, por 48 horas e no analisador por infravermelho em temperatura de $140{ }^{\circ} \mathrm{C}$. Os resultados obtidos foram tabulados e comparados entre si, para as amostras de lotes correspondentes. Verificou-se, pelo teste de Tukey, que não há diferença significativa entre os valores médios da umidade do sinter feed obtidos pelo método convencional e pelo método alternativo, utilizando o analisador de umidade por infravermelho. Também foi possível verificar, por meio da análise de variância, que não há diferenças significativas entre os dois tipos de metodologia. Em ambas as análises estatísticas, o nível de confiança foi de $95 \%$. Considerando que o tempo de análise pelo método convencional é de, no mínimo, seis horas e que o tempo médio de análise de uma amostra no analisador de infravermelho é de apenas dez minutos, a técnica alternativa mostra-se promissora para a determinação da umidade em carregamentos de sinter feed, antes do seu embarque para exportação, o que pode significar mais agilidade, com a mesma precisão do método convencional.
\end{abstract}

\section{INTRODUÇÃO}

O Brasil é um dos um dos maiores produtores de minério de ferro (13\% da produção mundial em 2015, o terceiro lugar no ranking) atrás apenas de China e Austrália, respectivamente. A maior parte da produção de minério de ferro no Brasil destina-se ao mercado externo, tendo a China como seu destino mais relevante. O material é exportando a partir de diversos portos nacionais e deve seguir rigorosos critérios de qualidade, estabelecidos por este tão importante mercado. (DNPM, 2016).

Um dos fatores limitadores do embarque de minério de ferro é o teor de umidade do material. Como são movimentadas grandes quantidades de minério, a verificação do teor de 


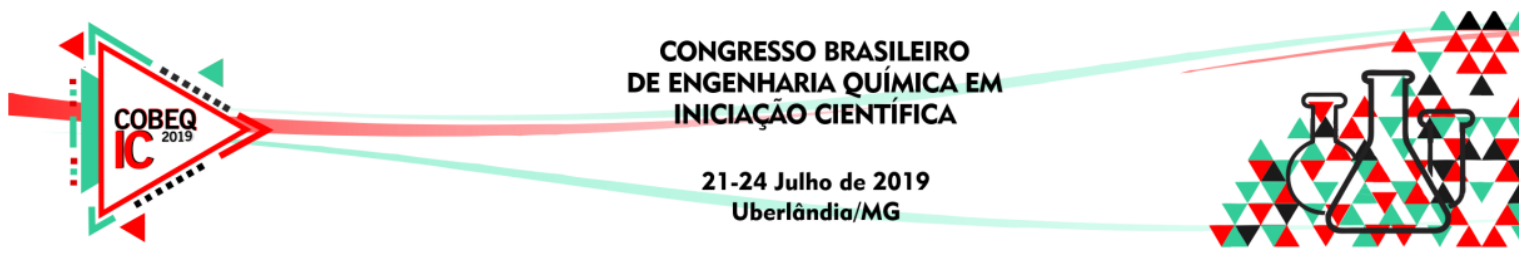

água contido nas partidas torna-se um problema tecnológico relevante e os métodos de determinação destes teores devem garantir o embarque do material dentro dos padrões exigidos.

Atualmente, a determinação do teor de umidade de um lote de minério de ferro é regulamentada pela norma técnica NBR ISO 3087:2011. Entretanto, a rotina de determinação da umidade do material leva não menos de seis horas para ser completada, o que retarda sobremaneira o embarque do material.

Neste trabalho foi feito um estudo comparativo entre a técnica estabelecida na norma NBR ISO 3087:2011 e o uso de um analisador de umidade por infravermelho, com vistas ao estabelecimento de uma rotina de determinação de umidade mais ágil e tão precisa quanto a atualmente empregada.

\section{REVISÃO DA LITERATURA}

A determinação do teor de água em amostras é um aspecto importante, quando se deseja estudar o comportamento físico e químico de uma substância ou material. Na indústria mineral, por exemplo, a determinação do teor de água também apresenta vantagem no aspecto de produção e da transação comercial. O seu conhecimento rigoroso pode levar a melhorias quanto à produção e distribuição desses produtos (THEMUDO, 1999).

Quanto à comercialização de minérios, o preço do minério de ferro é função de dois fatores: teor de ferro e umidade (influenciam no frete). Abatimentos sobre o preço podem ser aplicados quando os teores de contaminantes (sílica, alumina e fósforo) excedem um determinado limite, bem como prêmios pela qualidade do minério de ferro podem elevar seu preço (CUNHA, 2016).

A umidade representa para a indústria um custo indesejável. Segundo a empresa Vale, o minério de ferro embarcado no porto apresenta, em média, 9,5\% de umidade. O Valemax, maior mineraleiro do mundo, é capaz de transportar 400 mil toneladas por viagem. Nota-se, então, que nessas condições de umidade e capacidade total do navio, 38 mil toneladas de água saem dos portos e seguem para os principais clientes da empresa em diversas partes do mundo (ITV, 2017).

A água também representa um risco à segurança do transporte da carga. Existe uma legislação internacional que trata disto e que define um valor limite para a umidade, o Limite de Umidade Transportável (Transportable Moisture Limit - TML). Em casos extremos, as embarcações podem emborcar devido a rupturas, deslizamentos e liquefação da carga (FERREIRA et al., 2017).

A norma técnica que regulamenta a determinação do teor de umidade de um lote de minério de ferro é a NBR ISSO 3087:2011. Considerando a importância do estudo teórico da operação de secagem dos produtos de mineração e a limitação de informações teóricas a respeito dos fenômenos que ocorrem durante a secagem do sinter feed, este trabalho objetivou avaliar o uso do analisador de umidade por infravermelho para a determinação da umidade, como alternativa ao método padrão de estufa, que se baseia na secagem convectiva de uma 


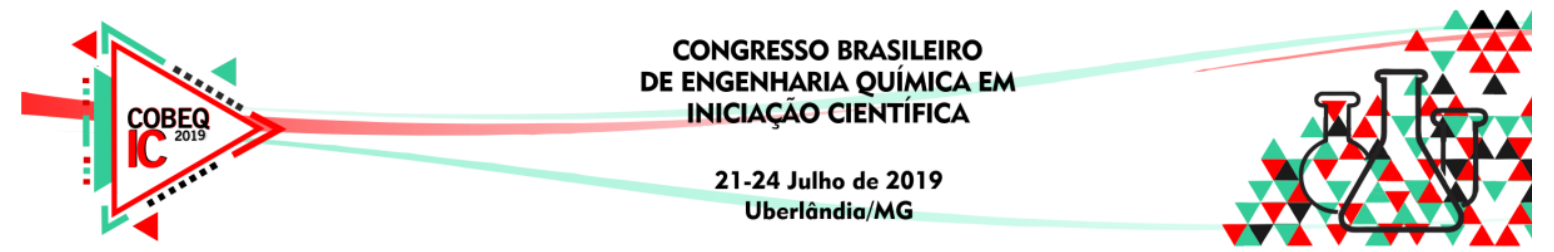

amostra homogeneizada de minério de ferro em estufa convencional, a $105^{\circ} \mathrm{C} \pm 5^{\circ} \mathrm{C}$, por, pelo menos seis horas.

\section{MATERIAL E MÉTODOS}

Como informado anteriormente, amostras de cerca de 3 a $5 \mathrm{~kg}$ de sinter feed, de 11 lotes distintos foram gentilmente cedidas pela empresa Ferrous Resources do Brasil. O material apresenta uma faixa granulométrica entre $6,35 \mathrm{~mm}$ e $0,15 \mathrm{~mm}$. Na Figura 1 são apresentadas amostras de sinter feed, conforme acondicionadas logo após descarregadas do trem.

Figura 1 - Amostras obtidas de lotes de diferentes trens, acondicionadas conforme foram cedidas para a realização desta pesquisa.

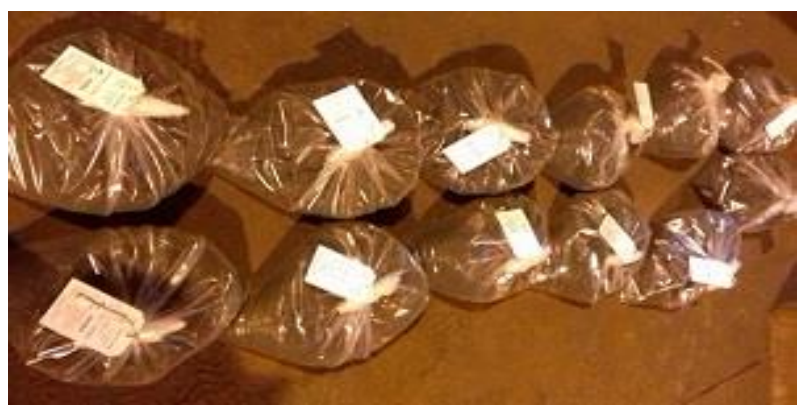

Nos experimentos realizados nesta pesquisa, 50,0 g de amostras de diferentes lotes de sinter feed foram pesadas em balança analítica, com o auxílio de formas previamente taradas, levadas à estufa ou ao analisador de umidade por infravermelho (ver Figura 2), visando a comparação entre os métodos.

Figura 2 - Foto, com vista interna do Analisador de Umidade Gehaka, modelo IV2000.

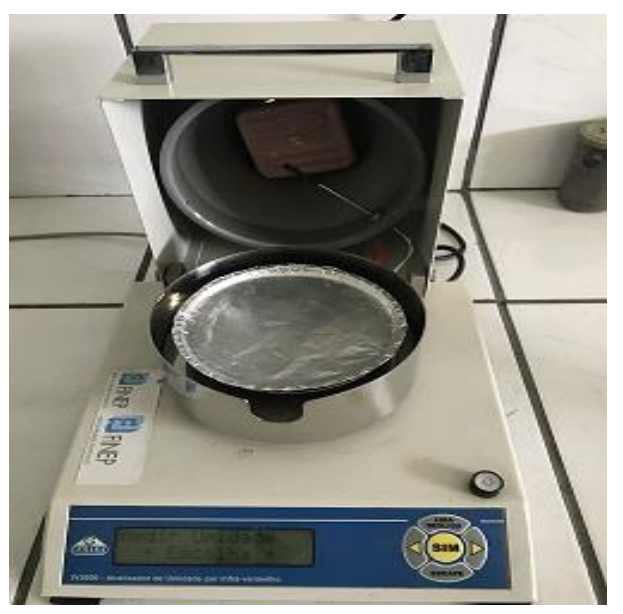




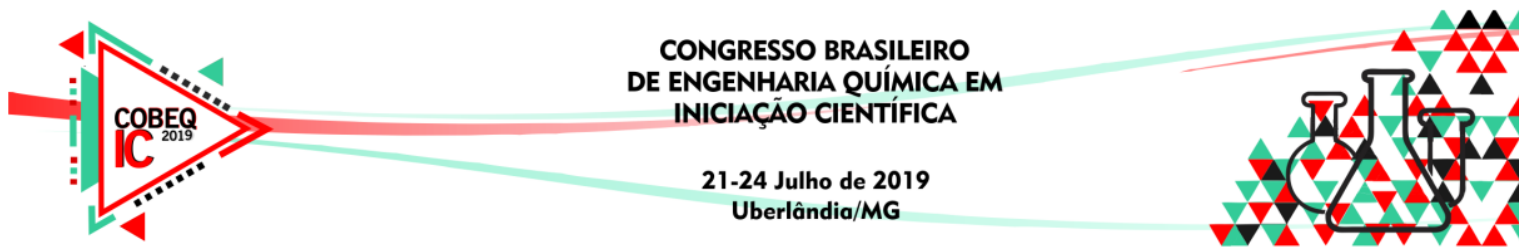

A temperatura de operação para a estufa e o analisador de umidade por infravermelho foi ajustada a $105^{\circ} \mathrm{C}$ e $140{ }^{\circ} \mathrm{C}$, respectivamente. Decidiu-se trabalhar com uma temperatura superior àquela da estufa no analisador de umidade por infravermelho, para verificar e, possivelmente, contestar a norma técnica, que adverte haver degradação do material acima de $105^{\circ} \mathrm{C}$.

O tempo de secagem para o método padrão de estufa foi de 48 horas, tempo superior àquele especificado na norma NBR ISSO 3087:2011, garantindo que a secagem foi feita até massa constante, o tempo médio de análise de cada amostra no analisador Gehaka IV2000 foi de, no máximo, 12 minutos. Os experimentos foram realizados em quadruplicata e os pontos experimentais foram identificados pelo código do trem e o número do lacre.

A fim de se verificar se os resultados obtidos nos dois equipamentos são equivalentes, o teste de Tukey, para médias, foi realizado para comparação entre os valores de umidade obtidos na estufa e no analisador de umidade por infravermelho, para cada lote. Também foi aplicada a análise de variância (ANOVA) ao conjunto dos resultados obtidos na estufa e no analisador, para verificar se há efeito significativo da mudança de metodologia para a determinação da umidade do sinter feed.

\section{RESULTADOS E DISCUSSÃO}

Na Tabela 1 são apresentados os valores médios da umidade do material ( $\mathrm{y}_{\mathrm{s}}$, em base úmida), obtidos na estufa convencional e no analisador de umidade por infravermelho, bem como os respectivos valores de desvio padrão (DP) e do coeficiente de variação $(\mathrm{CV})$.

Tabela 1 - Valores de umidade do sinter feed determinados e estufa e em analisador de umidade por infravermelho.

\begin{tabular}{|c|c|c|c|c|c|c|c|}
\hline \multicolumn{2}{|c|}{ Amostra } & \multicolumn{3}{|c|}{ Estufa } & \multicolumn{3}{|c|}{ Infravermelho } \\
\hline Código & Lacre & $\mathrm{y}_{\mathrm{s}}(\mathrm{b} . \mathrm{u})(\%)$ & DP & $\mathrm{CV}(\%)$ & $\mathrm{y}_{\mathrm{s}}(\mathrm{b} . \mathrm{u})(\%)$ & $\mathrm{DP}$ & $\mathrm{CV}(\%)$ \\
\hline NEH-3140 & $6704 / 10$ & 7,91 & 0,03 & 0,37 & 7,83 & 0,19 & 2,42 \\
\hline NEH-3126 & $6501 / 10$ & 9,42 & 0,09 & 0,92 & 9,48 & 0,05 & 0,53 \\
\hline NEH-3126 & $3205 / 07$ & 7,15 & 0,11 & 1,57 & 7,10 & 0,08 & 1,15 \\
\hline NEH-1108 & $6206 / 10$ & 11,71 & 0,16 & 1,40 & 11,55 & 0,19 & 1,66 \\
\hline NEH-3116 & $6402 / 10$ & 9,37 & 0,09 & 1,05 & 9,28 & 0,09 & 1,03 \\
\hline NEH-3128 & $6505 / 10$ & 8,52 & 0,13 & 1,48 & 8,53 & 0,09 & 1,12 \\
\hline NEH-3148 & $6810 / 10$ & 7,31 & 0,05 & 0,63 & 7,25 & 0,13 & 1,78 \\
\hline NEH-3152 & $7002 / 10$ & 8,87 & 0,16 & 1,84 & 8,73 & 0,15 & 1,72 \\
\hline NEH-0158 & $7007 / 10$ & 8,18 & 0,21 & 2,54 & 8,15 & 0,17 & 2,13 \\
\hline NEH-3162 & 7009/11 & 7,02 & 0,19 & 2,79 & 6,95 & 0,10 & 1,44 \\
\hline
\end{tabular}

Pela análise dos resultados apresentados na Tabela 1, verificou-se que a umidade dos diferentes lotes de sinter feed utilizados nesta pesquisa variou de 6,95 a $11,71 \%$ e que os coeficientes de variação para cada lote foram sempre inferiores a 2,8 \%, o que assegura a boa reprodutibilidade dos resultados em cada equipamento. 


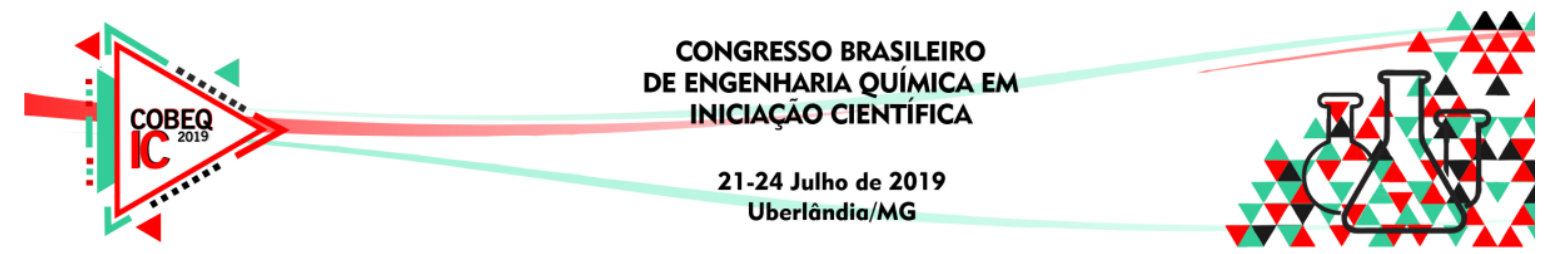

$\mathrm{Na}$ Tabela 2 são apresentados os valores de p-valor, $\mathrm{t}$-calculado (t-calc.) e t-tabelado ( $\mathrm{t}$ tab) obtidos para o teste de Tukey, para médias, entre os valores obtidos na estufa e no analisador de umidade por infravermelho, em cada lote.

Tabela 2- Resultados do teste de Tukey, para médias

\begin{tabular}{|cc|ccc|}
\hline \multicolumn{2}{|c|}{ Amostra } & \multicolumn{3}{c|}{ Teste de Tukey } \\
\hline Código & Lacre & p-valor & t-calc. & t-tab. \\
\hline NEH-3140 & $6704 / 10$ & 0,3889 & 0,9285 & 2,4469 \\
NEH-3126 & $6501 / 10$ & 0,2778 & $-1,1933$ & 2,4469 \\
NEH-3126 & $3205 / 07$ & 0,4747 & 0,7624 & 2,4469 \\
NEH-1108 & $6206 / 10$ & 0,2535 & 1,2629 & 2,4469 \\
NEH-3116 & $6402 / 10$ & 0,2289 & 1,3394 & 2,4469 \\
NEH-3128 & $6505 / 10$ & 0,9119 & $-0,1154$ & 2,4469 \\
NEH-3136 & $6505 / 10$ & 0,2331 & $-1,3258$ & 2,4469 \\
NEH-3148 & $6810 / 10$ & 0,3915 & 0,9231 & 2,4469 \\
NEH-3152 & $7002 / 10$ & 0,2395 & 1,3053 & 2,4469 \\
NEH-0158 & $7007 / 10$ & 0,8406 & 0,2099 & 2,4469 \\
NEH-3162 & $7009 / 11$ & 0,5721 & 0,5973 & 2,4469 \\
\hline
\end{tabular}

Como pode ser verificado na Tabela 2, partindo da hipótese de que a diferença entre as médias é nula, é possível constatar que não há diferença significativa entre os valores médios da umidade do sinter feed determinada na estufa convencional e no analisador de umidade por infravermelho, com $95 \%$ de confiança.

Outra constatação, a partir dos resultados apresentados na Tabela 2, é o fato de a determinação da umidade do sinter feed em temperatura acima da estabelecida pela norma NBR ISSO 3087:2011, não causa degradação do material, em oposição ao indicado na referida norma.

O conjunto completo de resultados referentes aos valores de umidade do sinter feed obtidos na estufa e no analisador de umidade por infravermelho foi submetido à análise de variância (ANOVA), para verificar se há efeito significativo do uso de metodologias diferentes na determinação da umidade deste material. Os resultados obtidos são apresentados na Tabela 3.

Tabela 3- Resultados da análise de variância (ANOVA)

\begin{tabular}{|lcccc|}
\hline Grupo & Contagem & Soma & Média & Variância \\
\hline Coluna 1 & 44 & 375,56 & 8,53 & 1,68 \\
Coluna 2 & 44 & 373,60 & 8,49 & 1,63 \\
\hline
\end{tabular}

\begin{tabular}{|lcccccc|}
\hline Fonte da variação & SQ & gl & MQ & F-calc. & p-valor & F-crítico \\
\hline Entre grupos & 0,04 & 1 & 0,0432 & 0,0261 & 0,8721 & 3,9519 \\
Dentro dos grupos & 142,43 & 86 & 1,6560 & & & \\
Total & $\mathbf{1 4 2 , 4 7}$ & $\mathbf{8 7}$ & & & & \\
\hline
\end{tabular}




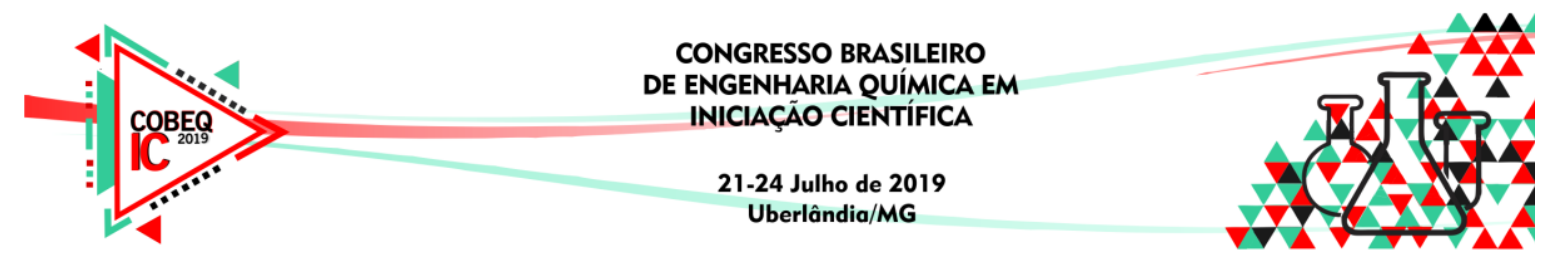

Assim como observado que não há diferença significativa entre as médias obtidas na estufa e no analisador de umidade por infravermelho, para cada lote, a análise de variância do conjunto total de dados obtidos permite verificar que não há diferença significativa entre os dois tratamentos, com $95 \%$ de confiança.

\section{CONCLUSÃO}

Com base nos resultados obtidos nesta pesquisa, conclui-se que o analisador de umidade por infravermelho Gehaka IV2000 foi capaz de determinar a umidade de cada lote de amostras consideradas com a mesma precisão da técnica convencional em estufa, não havendo diferenças significativas entre as médias, nem entre os dois tipos de tratamento, com nível de confiança de $95 \%$.

Considerando que o tempo de determinação da umidade pela técnica convencional é de, no mínimo, seis horas e que cada amostra pode ser processada no analisador de umidade por infravermelho em, no máximo, doze minutos, este equipamento pode ser considerado como uma técnica alternativa confiável e ágil para a determinar a umidade de sinter feed.

\section{REFERÊNCIAS}

AGUIAR, V. A. F.; Estudo da cinética de secagem e avaliação de metodologias para a determinação da umidade de sínter feed em analisador de umidade por infravermelho e em estufa. Monografia apresentada ao Departamento de Engenharia Química em 2018.

CUNHA, C. C. R. F. D. Determinação dos teores de água em amostras de minério de ferro, manganês e de oxihidróxidos de ferro sintéticos. Dissertação (Mestrado em Química) UFOP. Ouro Preto, p. 92. 2016.

DNPM. Sumário Mineral. Departamento Nacional de Produção Mineral. Brasília, p. 141. 2016. (ISSN 01012053 ).

FERREIRA, R. F. et al. Limite de umidade transportável de minério de ferro: aspectos regulatórios e técnicos. Tecnologia em metalurgia, materiais e mineração, São Paulo, jan-mar 2017. 16-23.

ITV. Redução da umidade do minério de ferro: inovações. Vale do Rio Doce, Belo Horizonte, 2017. Disponivel em: <http://www.itv.org/inovacao/reducao-da-umidade-do-minerio/>. Acesso em: 23 Agosto 2018.

THEMUDO, M. E. C. F. Aplicação do método de Karl Fischer a materiais que só libertam água a temperaturas elevadas. Dissertação (Mestrado em Química) - U.Porto. Porto, p. 85. 1999. 